\title{
Familial aggregation of undifferentiated spondyloarthropathy associated with HLA-B7
}

\author{
B L Kidd, P J Wilson, P R Evans, M I D Cawley
}

\begin{abstract}
Objective-To report multiple cases of recurrent seronegative arthropathy, enthesopathy, or both, occurring in a single family in the absence of the HLA-B27 tissue type, coexistent psoriasis or inflammatory bowel disease.

Methods-Three generations of one family together with their general practitioners completed a standard questionnaire. All subjects with a positive questionnaire and two randomly chosen subjects with negative questionnaires were then examined by a single observer. HLA tissue typing and standard sacroiliac radiographs were performed.
\end{abstract}

Results-Seven of 12 family members with a positive questionnaire had early onset oligo- or polyarthritis, enthesitis, or both, and fulfilled established criteria for spondyloarthropathy, although none had radiological evidence of sacroiliitis. The mean age at first symptom in this group was 22 years with only one individual having the first symptom over the age of 30 years. All subjects were rheumatoid factor negative. Histocompatibility studies showed a strong association with the HLA-B7 antigen.

Conclusions-The observations provide further support for the existence of 'undifferentiated' spondyloarthropathy and suggest that this can be associated with genetic factors other than HLA-B27.

Inflammation Research Group, London Hospital Medical College, London E1 2AD, United Kingdom B L Kidd

Wessex Immunohistocompatibility Service, Southampton General Hospital, Southampton SO9 4XY,

United Kingdom

P J Wilson

P R Evans

The Rheumatology

Unit

M I D Cawley

Correspondence to:

B L Kidd,
ARC Building,

ARC Building,

Londen Hospital Medical

Accepted for publication

9 September 1994
(Ann Rheum Dis 1995; 54: 125-127)

A number of rheumatic diseases with overlapping clinical features and evidence of familial aggregation have been clustered under the umbrella term 'spondyloarthropathy'. ${ }^{1}$ These diseases, which include ankylosing spondylitis (AS), reactive arthritis, psoriatic arthritis and enteropathic arthritis, have a strong but variable association with the histocompatibility antigen HLA-B27, and individuals with this antigen appear to have an increased risk of developing spondyloarthropathy. ${ }^{2}$

The term 'undifferentiated' spondyloarthropathy has been used to describe patients with features suggestive, but not diagnostic, of a spondyloarthritic disorder. ${ }^{3-5}$ These patients may have inflammatory spinal pain ${ }^{6}$ or asymmetric synovitis, together with a family history of a proven spondyloarthritic disease or sacroiliitis, enthesitis, or dactylitis. ${ }^{34}$ A preliminary set of criteria for spondyloarthropathy to include patients with undifferentiated disease have been proposed by the European Spondylarthropathy Study Group (ESSG). ${ }^{7}$ A greater prevalence of HLAB27 than in control populations has been reported in undifferentiated spondyloarthropathy, ${ }^{5}$ but it is apparent that other genetic factors may be implicated in this disorder.

In this report we describe a single family in which numerous family members shared the HLA-B7 antigen and had a recurrent seronegative arthropathy or enthesopathy, or both, which fulfilled ESSG criteria for spondyloarthropathy in the absence of psoriasis or inflammatory bowel disease.

\section{Subjects and methods}

Three generations of one family were assessed. One family member had died, but the remaining 19 were available for study. All subjects together with their general practitioners completed a questionnaire designed to obtain details of spinal or peripheral joint disease, psoriasis, enteric or genitourinary disease. All subjects with a positive questionnaire and two randomly chosen subjects with negative questionnaires were then reviewed by a single observer (BLK). A physical examination was performed which included measurement of spinal flexion (modified Shober method) and chest expansion, and assessment of peripheral joints and entheses for signs of inflammation.

A full blood count, erythrocyte sedimentation rate (ESR), rheumatoid and antinuclear factor screen were performed on all symptomatic subjects by standard methods. HLA tissue typing was performed by the standard two stage National Institutes of Health microlymphocytotoxicity test ${ }^{9}$ using well defined sera for common caucasian HLAA, HLA-B and HLA-DR1, 2, 3, 4, 5, w6, 7, w8 and 9 antigens. Standard sacroiliac radiographs were performed which were then assessed independently by a skeletal radiologist. They were graded using the Atlas of Standard Radiographs in Arthritis. ${ }^{10}$

\section{Results}

The pedigree in the figure presents the HLA haplotypes. Twelve family members had 


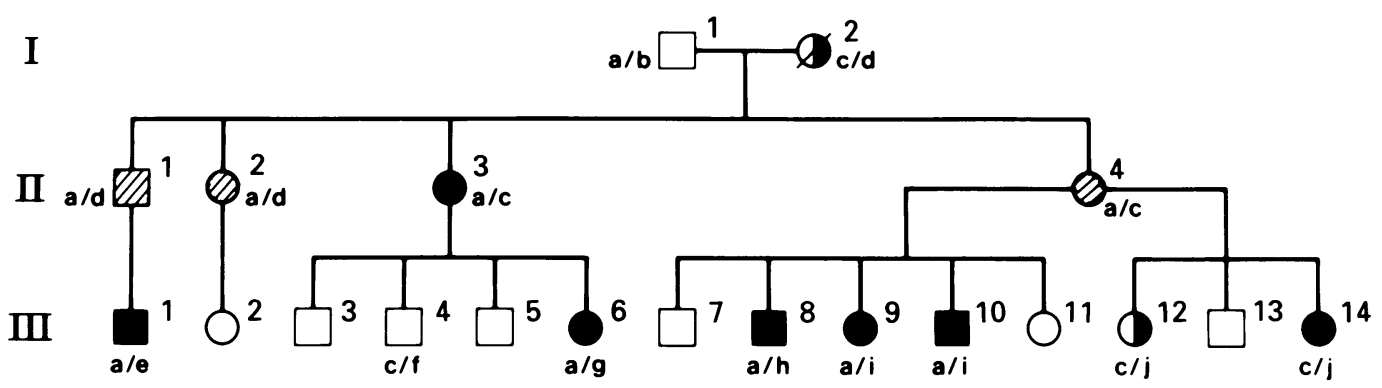

$$
\begin{aligned}
& \text { Early onset synovitis } \\
& \text { Late onset synovitis } \\
& \text { Spinal pain }
\end{aligned}
$$

Family pedigree depicting clinical features and HLA haplotypes. $a=A 3 B 7 D R 5 ; b=A 3 B 7 D R 2 ; c=A 11 B 7 D R 2 ;$ $d=A 32$ B44 DR2; $e=A 29$ B44 DR4; $f=A 2$ B44 DR4; $g=A 2$ B17 DR7; $h=A 3$ B15 DR5; $i=A 32$ B27 DR4; $j=A 32 B 17$ DR2.

symptoms or signs of musculoskeletal disease (table). None of the family members examined was rheumatoid or antinuclear factor positive and none had evidence of psoriasis or inflammatory bowel disease.

The index case (III.9) was a 27 year old woman who presented at eight years of age with intermittent synovitis of both wrists, and subsequent involvement of both hips, knees and ankles. At the age of 17 she developed lumbar pain with morning stiffness. The highest recorded ESR was $22 \mathrm{~mm} / 1 \mathrm{st} \mathrm{h}$. When reviewed she had active synovitis in both knees and wrists. Spinal movements were normal. Radiographs of the sacroiliac joints, lumbar spine, and peripheral joints were normal.

An older brother (III.8), aged 31, had had intermittent pain in the left ankle and both knees since 18 years of age. Clinically he had bilateral Achilles tendon enthesopathy. Radiographs were normal. A younger brother (III.10), aged 24, had had bilateral knee swelling since the age of 14 . He developed recurrent mouth ulceration and inflammatory type lumbar pain at 20 years of age. Clinically, he had normal spinal movement and no peripheral signs. Sacroiliac radiographs were normal.

\begin{tabular}{|c|c|c|c|c|c|c|c|}
\hline No & Sex & $\begin{array}{l}\text { Principal } \\
\text { feature }\end{array}$ & $\begin{array}{l}\text { Age at } \\
\text { onset } \\
\text { (yr) }\end{array}$ & Enthesitis & $\begin{array}{l}\text { Inflamm. } \\
\text { back } \\
\text { pain }^{6}\end{array}$ & $\begin{array}{l}\text { Maximum } \\
\text { ESR } \\
(\mathrm{mm} / 1 \mathrm{st} h)\end{array}$ & $\begin{array}{l}\text { ESSG } \\
\text { criteria }^{7}\end{array}$ \\
\hline I. 1 & $\mathbf{M}$ & No abnormality & & & & & \\
\hline I. 2 & $\mathrm{~F}$ & Cervical pain & 50 & - & - & NA & - \\
\hline II. 1 & $M$ & Oligoarthritis & 56 & - & - & 23 & - \\
\hline II. 2 & $\mathrm{~F}$ & Polyarthritis & 51 & + & - & 11 & + \\
\hline II. 3 & $\mathrm{~F}$ & Polyarthritis & 17 & + & - & 36 & + \\
\hline II. 4 & $\mathrm{~F}$ & Monarthritis & 50 & - & - & 25 & - \\
\hline III. 1 & M & Oligoarthritis & 37 & - & - & NA & - \\
\hline III. 2 & $\mathrm{~F}$ & No abnormality & & & & & \\
\hline III. 3 & $M$ & No abnormality & & & & & \\
\hline III.4 & $M$ & No abnormality & & & & & \\
\hline III. 5 & $M$ & No abnormality & & & & & \\
\hline III.6 & $\mathrm{F}$ & Polyarthritis & 20 & + & - & 37 & + \\
\hline III.7 & $M$ & No abnormality & & & & & \\
\hline III. 8 & $M$ & Oligoarthritis & 18 & + & - & 17 & + \\
\hline III. 9 & $\mathrm{~F}$ & Polyarthritis & 8 & - & + & 22 & + \\
\hline III. 10 & $M$ & Oligoarthritis & 14 & - & + & 23 & + \\
\hline III. 11 & $\mathrm{~F}$ & No abnormality & & & & & \\
\hline III. 12 & $\mathrm{~F}$ & Lumbar pain & 19 & - & - & 12 & - \\
\hline III. 13 & $M$ & No abnormality & & & & & \\
\hline III. 14 & $\mathrm{~F}$ & Oligoarthritis & 28 & + & + & 21 & + \\
\hline
\end{tabular}

A half-sister (III.12), aged 41, had intermittent low back pain since her late teens. There were no clinical or radiological abnormalities. Another half-sister (III.14), aged 36 , had inflammatory type lumbar pain associated with right heel and wrist pain since the age of 28. Clinically, she had reduced lumbar flexion, bilateral sacroiliac tenderness, right plantar fascilitis and Achilles tendonitis. Sacroiliac radiographs were normal. Their mother (II.4) had been seen by a rheumatologist when aged 50 , for swelling in the right knee. All investigations were normal.

One cousin (III.6), aged 43, had intermittent pain and swelling in the shoulders, hips, knees and ankles since the age of 20 . She noted marked improvement during pregnancy. Clinically, she had irritable hips, bilateral knee effusions and a right Achilles tendon enthesopathy. She had normal radiographs. Another cousin (III.1), aged 43 years, had a six year history of intermittent swelling and pain in the right first and third toes and left thumb. Clinically, he had a dactylitis of the third right toe. He was radiologically normal.

An aunt (II.3), aged 65, presented with synovitis of the wrists, hips, knees and ankles at the aged of 17 . She was initially treated with gold injections and later with steroids. She had been investigated for chronic dysuria, although the cause remained unclear. Clinically, she had synovitis in the wrists and knees, with bilateral Achilles tendinitis and pain on pressure over the right sacroiliac joint. Radiographs of her peripheral joints showed degenerative changes, with no evidence of erosive disease.

A second aunt (II.2), aged 63, gave a 12 year history of pain in the hands, wrists, knees, ankles and toes. Clinically she had synovitis involving both wrists with a left Achilles tendon enthesopathy. She had normal radiographs. An uncle (II.1) complained of intermittent polyarthritis involving the left knee and both first MTP joints diagnosed as gout by the family physician (serum uric acid $0.42 \mathrm{mmol} /$ 1). He had been investigated for dysuria when aged 43 years. Sacroiliac radiographs were normal. A maternal grandparent (I.2) had died at the age of 81 years, having complained of 
cervical and thoracic pain during the last 30 years of life. Radiographs performed by the general practitioner were consistent with her age.

\section{Discussion}

The concept of undifferentiated spondyloarthropathy remains unproven, but there is substantial clinical evidence to support the existence of this disorder. Lawrence and Bennett were the first to draw attention to a benign, seronegative arthritis, which they called benign polyarthritis. ${ }^{11}$ More recently, Burns et al studied 599 first degree relatives of 223 probands with AS or Reiter's syndrome ${ }^{3}$ and reported that $61(10.2 \%)$ had disease manifestations of a spondyloarthropathy, including 20 with a disorder characterised by enthesitis, isolated dactylitis, unilateral sacroiliitis, or asymmetric peripheral arthritis. Similar groups have been described by others. ${ }^{812}$

Seven of the 12 family members with musculoskeletal disease fulfilled the ESSG criteria for spondyloarthropathy, ${ }^{7}$ although none had evidence of anklyosing spondylitis. There is the possibility that, rather than having an undifferentiated spondyloarthropathy, they were manifesting a variant of skeletal hyperplasia, although this seems relatively unlikely. The mean age at first symptom in this group was 22 years (range 8-51 years), with only one individual having the first symptom over the age of 30 years. In most cases modest increases in the ESR had been recorded at some stage but, despite quite longstanding disease, no erosive or other destructive changes were noted on peripheral or sacroiliac joint radiographs.

In this family, six of the seven individuals with early onset disease had the haplotype HLA A3 B7 DR5. The only exception (subject III.14) had the haplotypes HLA A11 B7 DR2 and A32 B17, DR2. All affected individuals therefore shared the histocompatibility antigen B7. This antigen is a member of the B7-CREG antigen group which includes B7, B22, B40 and $\mathrm{B} 42^{13}$ and it is relevant that many HLAB27 negative ankylosing spondylitis patients carry one or more of these antigens. ${ }^{14}$ Since the B7-CREG group shares a common epitope, it has been speculated that this epitope could be the disease determinant rather than a specific allele, although this remains unproven. ${ }^{14}$ It is noteworthy that two individuals had HLA-B27 and fulfilled criteria for inflammatory back pain. Allelic synergism has been shown to be operating between HLA-B27 and HLA-Bw60 (B40) in several patients with ankylosing spondylitis ${ }^{15}$ and it is interesting to speculate that similar synergism may be operating here.

In conclusion, we can find no reports of multiple cases of a recurrent seronegative arthropathy occurring in a single family in the absence of additional factors such as psoriasis, inflammatory bowel disease or a family history of a recognised spondyloarthropathy. In this respect we believe the present study to be unique.

1 Moll J M H, Haslock I F, Wright V. The associations between ankylosing spondylitis, Reiter's disease, the intestinal arthropathies, and Behçet's syndrome. Medicine 1974; 53: 343-64.

2 Espinoza R, Vasey F B, Gaylord S W, et al. Histocompatibility typing in the seronegative spondyloarthropathies: a survey. Semin Arthritis Rheum 1982; 11: 375-81.

3 Burns T, Marder A, Becks E, Calin A. Undifferentiated spondylarthritis: A nosological missing link? Arthritis spondylarthritis: A nosological

4 Zeidler H. Undifferentiated arthritis and spondylarthropathy as a major problem of diagnosis and classification. Scand f Rheum 1987; (suppl 65): 54-62.

5 Burns M, Calin A. Undifferentiated spondylarthropathy. In: Calin A, ed. The spondylarthropathies. Orlando, Florida: Grune and Stratton, 1984; 253-64.

6 Calin A, Porta J, Fries J F, Schuerman D J. Clinical history as a screening test for anklosing spondylitis. $\mathfrak{F} A M A 1977$; 237: 2613-4.

7 Dougados $M$, van der Linden S, Juhlin $R$, et al. The European Spondylarthropathy Study Group preliminary criteria for the classification of spondylarthropathy. Arthritis Rheum 1991; 34: 1218-30.

8 Prakash S, Mehra N K, Bhargava S, Malaviya A N. HLA B27 related "unclassifiable" seronegative spondylB27 related "unclassifiable" seronegative

9 Terasaki P I, Bernoco D, Park M S, Ozturk G, Iwaki Y. Microdroplet testing for HLA-A, -B, -C, and -D antigens. Am F Clin Pathol 1978; 69: 103-20.

10 Kellgren J H, Jeffrey M R. Epidemiology of chronic rheumatism. In: Atlas of standard radiographs in arthritis, Vol II. Oxford: Blackwell Scientific Publications, 1963; $36-40$

11 Lawrence J S, Bennett P H. Benign polyarthritis. Ann Rheum Dis 1960; 19: 20-3.

12 Eastmond C J, Rajah S M, Tovey D, Wright V. Seronegative pauciarticular arthritis and HLA B27. Ann Rheum Dis 1980; 39: 231-4.

13 Arnett F C, Hochberg M C, Bias W B. Cross reactive antigens in B27 negative Reiter's syndrome and antigens in B27 negative Reiter's syndrome

14 McLain D A, Luehrman L K, Rody G E, Schwartz. An HLA public antigen is more important than HLA-B27 in patients with ankylosing spondylitis. Arthritis Rheum 1980; 23: 718

15 Robinson W P, van der Linden S M, Khan M A, et al. HLABw60 increases susceptiblity to ankylosing spondylitis in HLA-B27+ patients. Arthritis Rheum 1989; 32: 1135-41. 